\title{
Current Perspectives and Novel Strategies of NRAS-Mutant Melanoma
}

\section{Alejandro Garcia-Alvarez \\ Carolina Ortiz \\ Eva Muñoz-Couselo}

Vall d'Hebron University Hospital, Medical Oncology Department, Melanoma and Other Skin Tumors Unit, Vall Hebron Institute of Oncology (VHIO), Barcelona, 08035, Spain
Correspondence: Eva Muñoz-Couselo Vall d'Hebron University Hospital, Medical Oncology Department,

Melanoma and Other Skin Tumors Unit, Vall Hebron Institute of Oncology

(VHIO), Pg Vall d'Hebron, II9-129,

Barcelona, 08035, Spain

Tel +934894350

Fax +93 274678I

Email emunoz@vhebron.net
Abstract: Melanoma is the deadliest cutaneous cancer. Activating mutations in $N R A S$ are found in $20 \%$ of melanomas. NRAS-mutant melanoma is more aggressive and, therefore, has poorer outcomes, compared to non-NRAS-mutant melanoma. Despite promising preclinical data, to date immune checkpoint inhibitors remain the standard of care for locally advanced unresectable or metastatic NRAS melanoma. Data for efficacy of immunotherapy for NRAS melanoma mainly come from retrospective cohorts with divergent conclusions. MEK inhibitors have been the most developed targeted therapy approach. Although associated with an increase in progression-free survival, MEK inhibitors do not provide any benefit in terms of overall survival. Combination strategies with PI3K-AKT-mTOR pathway and CDK4/6 inhibitors seem to increase MEK inhibitors' benefit. Nevertheless, results from clinical trials are still prelaminar. A greater comprehension of the biology and intracellular interactions of $N R A S$-mutant melanoma will outline novel impactful strategies which could improve prognosis of these subgroup of patients.

Keywords: metastatic melanoma, NRAS mutation, MEK inhibitor, immunotherapy

\section{Introduction}

With 324,635 new diagnoses and 57,043 deaths worldwide during 2020, cutaneous melanoma constitutes the 17 th most incident and the 22 nd most deadly malignancy. These data vary around the continents due to heterogenous frequency of skin phototype, with higher rates of both incidence and mortality in Oceania, Western Europe and Northern America. ${ }^{1}$ Although mortality tends to stabilize, melanoma incidence has been rising over the last 40 years. $^{2}$

An integrative analysis of cutaneous melanomas performed by the TCGA (The Cancer Genome Atlas) network validated four genomic subtypes characterized by $B R A F, N R A S, N F 1$ mutations and a "triple wild-type" subgroup (which includes KIT mutated melanoma). ${ }^{3}$ Improvement in the understanding of cutaneous melanoma's biology together with clinical benefit of BRAF-targeted therapy ${ }^{4-6}$ and immunotherapy ${ }^{7-10}$ over the last decade have changed the therapeutic management of advanced melanoma. However, not many progresses have been made in developing novel therapeutic options for BRAF wild-type melanomas.

NRAS mutant melanoma comprises $20 \%$ of all melanoma, ${ }^{3}$ which appears to confer an aggressive course compared with $B R A F$-mutant or $R A F$ and NRAS wildtype melanomas. ${ }^{11}$ In this setting, effective treatment options for this population are required, especially after disease progression on immunotherapy with anti-CTLA4 and/or anti-PD-1 antibodies. MEK inhibitors have been the most exploited treatment option in clinical trials with limited efficacy compared to chemotherapy. ${ }^{12}$ 
A greater comprehension of the biology and intracellular interactions of NRAS-mutant melanoma will outline novel impactful strategies which could improve prognosis of these subgroup of patients.

\section{Ras as an Oncogene in Melanoma}

Activating mutations in the Ras GTPase proteins have been found in one-third of human cancers. ${ }^{13}$ Ras is a superfamily of proteins implicated in cell growth, survival and differentiation, sending intracellular signals from receptor tyrosine kinases (RTK) to the MAPK (mitogenactivated protein kinase) and PI3K (phosphoinositide 3-kinase)-AKT pathways mainly. ${ }^{14}$

Three RAS isoforms (NRAS, neuroblastoma ras viral oncogene homolog; KRAS, Kirsten rat sarcoma viral oncogene homolog; and HRAS, Harvey rat sarcoma viral oncogene homolog) have been described and frequently harbor oncogenic mutations in cancer. ${ }^{15}$ Regarding cutaneous melanoma, aside from NRAS, we find mutations in KRAS and HRAS accounting for $2 \%$ and $1 \%$ of the cases, respectively. ${ }^{3}$

\section{NRAS Melanoma}

$N R A S$ was the first oncogene recognized in melanoma ${ }^{16}$ and mutations in NRAS account for $20 \%$ of all melanomas. ${ }^{3}$ $N R A S$ and $B R A F$ mutations are usually mutually exclusive. ${ }^{3}$

$N R A S$ mutations primarily occur at position 61 and involve amino acid change from glutamine $(\mathrm{Q})$ to arginine $(\mathrm{R})$, lysine (K) or leucine $(\mathrm{L}) .{ }^{17}$ These mutations block NRAS into a GTP-bound state impairing its GTPase activity. ${ }^{18}$

Mutations at codons 12 or 13 mutations comprise $20 \%$ of all NRAS and result in amino acid change from glycine $(\mathrm{G})$ to aspartic acid (D) ${ }^{17}$ These mutations prevent the association of GAPase activating proteins (GAP) to NRAS and are more frequent in mucosal melanoma than cutaneous melanoma. ${ }^{18}$

NRAS mutations results in an endless activation of the MAPK signaling and hardly ever concur with mutations in the PI3K-AKT pathways, indicating that NRAS could modulate this pathway too. ${ }^{19}$ These pathways cause dysregulation of cell-cycle and cellular proliferation signals. ${ }^{14}$

$N R A S$-mutant melanoma differs from BRAF-mutant melanoma from a clinical point of view. Patients are usually older ( $>55$ years) with previous UV exposure. ${ }^{20}$ Lesions have predisposition to the upper extremities and are thicker with higher Breslow depth. ${ }^{11,20}$

Regarding prognosis, similar to $B R A F$-mutant melanoma, NRAS mutation has been related to aggressive disease traits and with an increased risk of visceral and brain involvement. ${ }^{21,22}$

\section{Immunotherapy for NRAS Melanoma}

Despite all the translational and clinical data gathered since discovery of NRAS mutation as a driver in melanoma, ESMO guidelines recommend treatment with immune checkpoint inhibitors (anti-CTLA4 and/or antiPD1 inhibitors) as standard of care for the locally advanced unresectable and metastatic staging. ${ }^{23}$

However, data from pivotal trials which led to approval of immune checkpoint inhibitors in melanoma did not report outcomes for NRAS subgroup. Data for efficacy of immunotherapy for NRAS melanoma mainly comes from retrospective cohorts. Tables 1 and 2 summarize all reported results.

In a first cohort of $236 N R A S$-mutant patients from five skin cancer centers in Germany and Switzerland have been treated with Ipilimumab, anti-PD1 or anti-PD1+Ipilimumab combination. Efficacy outcomes for each treatment group are depicted in Table 1. Comparison to NRAS wild-type subgroup $(\mathrm{n}=128)$ evidenced comparable overall response rate (ORR) and disease control rate (DCR) and significantly lower overall survival (OS) (Table 2). ${ }^{24}$

An independent cohort of 162 patients with NRASmutant melanoma from 11 referral centers in Italy treated in first line with immunotherapy reported different results. Cumulative results irrespective of treatment option showed a PFS (progression free survival) of 12 months, OS of 32 months and ORR of $42 \%$. No differences in all efficacy outcomes were seen compared with 169 patients with $B R A F / N R A S$ wild type melanoma (Table 2). ${ }^{25}$

Finally, a cohort of 60 patients treated with anti-PD1 /PD-L1 or Ipilimumab in first or second line also reported cumulative efficacy outcomes. Median PFS was 4.1 months, median OS was 19.5 months and ORR were $64 \%$ and $19 \%$ for anti-PD1/PD-L1 and Ipilimumab, respectively. Compared to a cohort of 169 patients (53 with BRAF V600 mutation and 116 BRAF/NRAS wild type), immunotherapy for NRAS mutant patients increased DCR, which did not translate into longer PFS and OS. ${ }^{26}$

Regarding efficacy of anti-PD1+anti-CTLA4 combination compared with anti-PD1 monotherapy in NRAS melanoma, in a cohort of 69 patients treated in first line for unresectable and/or metastatic disease, combination significantly longer PFS (not reached vs 7 months) and a nonsignificant trend towards prolonged OS (not reached vs 21.9 months). ${ }^{27}$

Given the different outcomes regarding NRAS-mutant melanoma response to immunotherapy, prospective series 
Table I Summary of Efficacy Outcomes of Immunotherapy (Monotherapy and Combinations) in Patients with NRAS-Mutant Melanoma from Retrospectives Cohorts

\begin{tabular}{|c|c|c|c|c|c|}
\hline Cohort & NRAS-Mutant Melanoma Patients & ORR & DCR & PFS & OS \\
\hline I. Kirchberger et $\mathrm{al}^{24}$ & $\begin{array}{l}\text { - IPI: I25 pts. } \\
\text { - PDI: } 34 \text { pts. } \\
\text {-Combo: } 77 \text { pts. }\end{array}$ & $\begin{array}{c}\text { - IPI: I5\% } \\
\text { - PDI: } 21 \% \\
\text { - Combo: } 40 \%\end{array}$ & $\begin{array}{c}\text { - IPI: } 27 \% \\
\text { - PDI: } 35 \% \\
\text { - Combo: } 61 \%\end{array}$ & NR & $\begin{array}{c}\text { - IPI: I2 mo } \\
\text { - PDI: } 18 \mathrm{mo} \\
\text { - Combo: } 32 \mathrm{mo}\end{array}$ \\
\hline 2. Guida et $\mathrm{al}^{25}$ & $\begin{array}{l}\text { - IPI: } 45 \text { pts. } \\
\text { - PDI: II } 4 \text { pts. } \\
\text {-Combo: } 3 \text { pts. }\end{array}$ & $\begin{array}{c}\text { - IPI: } 36 \% \\
\text { - PDI: } 43 \% \\
\text { - Combo: NR }\end{array}$ & $\begin{array}{c}\text { - IPI: } 36 \% \\
\text { - PDI: } 68 \% \\
\text { - Combo: NR }\end{array}$ & $\begin{array}{l}\text { - IPI: } 4 \text { mo. } \\
\text { - PDI: I5 mo. } \\
\text { - Combo: NR }\end{array}$ & $\begin{array}{l}\text { - IPI: } 26 \text { mo. } \\
\text { - PDI: } 32 \text { mo. } \\
\text { - Combo: NR }\end{array}$ \\
\hline 3. Johnson et $\mathrm{al}^{26}$ & $\begin{array}{c}\text { - IPI: } 38 \text { pts. } \\
\text { - PDI/LI: } 8 \text { pts. }\end{array}$ & $32 \%$ & $50 \%$ & 4.I months & 19.5 months \\
\hline
\end{tabular}

Abbreviations: ORR, overall response rate; DCR, disease control rate; PFS, progression free survival; OS, overall survival; IPI, Ipilimumab; PDI/LI, anti-PDI or anti-PD-LI antibody; Combo, combination of anti-PDI with Ipilimumab; Mo, months; NR, not reported.

Table 2 Summary of Efficacy Outcomes of Immunotherapy (Monotherapy and Combination) in Patients with NRAS-Mutant Melanoma Compared to Other Non-NRAS Mutant Melanoma Patients

\begin{tabular}{|c|c|c|c|c|c|}
\hline Cohort & Patients & ORR & DCR & PFS & OS \\
\hline I. Kirchberger et $\mathrm{al}^{24}$ & $\begin{array}{l}\text { - NRASmt: } 236 \\
\text { - NRASwt: } 128\end{array}$ & $\begin{array}{c}\text { - IPI: } 15 \% \text { vs } \\
13 \% \\
\text { - PDI: } 21 \% \text { vs } \\
13 \% \\
\text { - Combo: } 40 \% \\
\text { vs } 39 \%(p=n s)\end{array}$ & $\begin{array}{c}\text { - IPI: } 27 \% \text { vs } \\
40 \% \\
\text { - PDI: } 35 \% \text { vs } \\
25 \% \\
\text { - Combo: } 61 \% \\
\text { vs } 73 \%(p=n s)\end{array}$ & NR & 21 vs $33 \mathrm{mo}(p=0.034)$ \\
\hline 2. Guida et $\mathrm{al}^{25}$ & $\begin{array}{c}\text { - NRASmt: } 162 \\
\text { - NRAS/BRAFwt: } 169\end{array}$ & $\begin{array}{c}42 \% \text { vs } 37 \% \\
\quad(p=0.38)\end{array}$ & $\begin{array}{c}60 \% \text { vs } 59 \% \\
(p=0.90)\end{array}$ & 12 vs 9 months $(p=0.51)$ & 32 vs $27 \mathrm{mo}(\mathrm{p}=\mathrm{ns})$ \\
\hline 3. Johnson et $\mathrm{al}^{26}$ & $\begin{array}{c}\text { - NRASmt: } 60 \\
\text { - BRAFmt: } 53 \\
\text { - NRAS/BRAFwt: II6 }\end{array}$ & $\begin{array}{c}32 \% \text { vs } 23 \% \text { vs } \\
19 \%(p=0.06)\end{array}$ & $\begin{array}{l}50 \% \text { vs } 30 \% \text { vs } \\
29 \%(p=0.004)\end{array}$ & $\begin{array}{l}4.1 \text { vs } 2.9 \mathrm{mo}(\mathrm{NRASmt} \text { vs } \\
\text { non-NRAS; } \mathrm{p}=0.08)\end{array}$ & $\begin{array}{l}19.5 \text { vs } 15.2 \text { mo }(\text { NRASmt } \\
\text { vs non-NRAS; } \mathrm{p}=0.5 \mathrm{I})\end{array}$ \\
\hline
\end{tabular}

Abbreviations: ORR, overall response rate; DCR, disease control rate; PFS, progression free survival; OS, overall survival; IPI, Ipilimumab; PDI/LI, anti-PDI or anti-PD-LI antibody; Combo, combination of anti-PDI with Ipilimumab; Mo, months; NR, not reported; Mt, mutant; Wt, wild type.

are needed to clarify if immune checkpoint inhibitors improve outcomes in this population.

\section{Strategies in Clinical Trials for NRAS Melanoma}

\section{Farnesyl-Transferase Inhibitors}

NRAS needs to undergo post-translational modifications in order to be active. Farnesylation of a cysteine allows the insertion of NRAS into the cellular membrane and its ulterior activation. $^{28}$

Farnesyl transferase inhibitors have shown promising preclinical activity. ${ }^{29,30}$ Regrettably, these results did not translate into a clinical benefit from lonafarnib ${ }^{31}$ and tipifarnib ${ }^{32}$ in solid tumors with NRAS and KRAS mutations.
In melanoma, R115777 was tested in a Phase II trial enrolling 14 patients. No data about their NRAS status was reported. Unfortunately, no response was evidenced to the farnesyl transferase inhibitor. ${ }^{33}$

The lack of success observed appears to be related to alternative prenylation by geranylgeranyltransferase I (GGTase I) in the alternative prenylation. ${ }^{34}$ Farnesyl transferase and GGTase I inhibitors combinations have been evaluated in clinical trials with concerns regarding toxicity. ${ }^{35}$

\section{MEK Inhibitors}

Due to the absence of direct NRAS inhibitors, focus moved towards targeting downstream effectors of the MAPK pathway, with MEK $1 / 2$ inhibitors (MEKi). ${ }^{36}$ The 
use of MEKi is to date the most investigated approach. These drugs are oral, competitive or non-competitive, allosteric inhibitors of MEK. ${ }^{36}$

Third-generation MEKi development have led to evaluation of drugs such as trametinib (GSK1120212) ${ }^{37}$ and

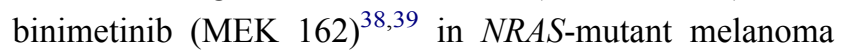
patients.

The Phase I study of trametinib included seven patients with NRAS-mutant melanoma. Stable disease in two patients $(29 \%)$ was the best response achieved. ${ }^{37}$ No further development was done for trametinib in NRASmutant melanoma. Combination strategies of trametinib with novel agents could play a role in future clinical trials for $N R A S$-mutant patients.

On the other hand, the phase II trial of binimetinib

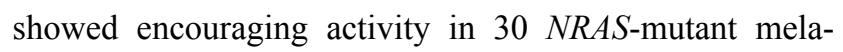
noma patients with an ORR of $20 \%$ and a median PFS of 3.7 months. $^{38}$ Taking into account these results, a randomized Phase III trial (NEMO trial) was undergone in 402 NRAS mutated melanoma patients. Binimetinib significantly increased ORR (7\% vs 15\%) and PFS (1.5 vs 2.8 months; Hazard Ratio 0.62) compared to dacarbazine. However, no differences in terms of OS were observed. ${ }^{39}$ Based on these results, binimetinib monotherapy did not received approval for the treatment of $N R A S$ mutant melanoma.

Other MEKi such as pimasertib (AS703026) ${ }^{40}$ or RO4987655 $5^{41}$ have also been tested for efficacy. Pimasertib was evaluated in a randomized phase II trial with 194 NRAS-mutant patients versus Dacarbazine. A significant benefit for pimasertib was observed, with a mPFS of 13.0 weeks (vs 6.9 weeks) and a DCR of $37.7 \%$ (vs 26.6\%). Once more, no differences in OS were observed (8.9 vs 10.6 months). ${ }^{40}$ RO4987655 $(\mathrm{CH} 4987655)$ has also been tested in a phase I trial enrolling 8 patients with $N R A S$-mutant melanoma. ORR was $13 \%$ with partial response (PR) as best responses. ${ }^{41}$

\section{RAF Inhibitors}

RAF isoforms (ARAF, BRAF and CRAF) are the downstream effector after RAS proteins in the MAPK pathway. $N R A S$-mutant melanoma is refractory to BRAF inhibitors. BRAF inhibitors induce paradoxical activation of the MAPK pathway due to CRAF-mediated ERK phosphorylation. ${ }^{42,43}$

Pan-RAF inhibitors have emerged as an option for RAS or RAF mutant tumors. LY3009120, a pan-RAS inhibitor, has been assessed in the setting of a phase I clinical trial which enrolled a total of 51 patients.
Regarding molecular subgroups, only 5 patients with NRAS-mutant tumors (4 melanoma and 1 breast cancer patients) were included, with only $1 \mathrm{SD}$ as best response. Given the lack of efficacy and the unfavorable toxicity profile, LY3009120 further development has been discontinued. ${ }^{44}$ Belvarafenib, a novel pan-RAF inhibitor, is under phase I evaluation and its results are awaited. ${ }^{45}$

In order to increase pan-RAF efficacy, preclinical combination with MEK inhibitors has been investigated. Pan-RAF inhibitor (Amgen Compd A) and Trametinib combination was found to significantly enhance cell growth inhibition and suppress MAPK activation (evaluated by p-ERK Western blotting) compared to monotherapy in NRASmutant melanoma cell lines. Efficacy seem to be associated with MAPK dependency and the presence of MAPKindependent pro-survival and anti-apoptotic signals. ${ }^{46}$

\section{PI3K-AKT-mTOR Pathway Inhibitors}

PI3K-AKT-mTOR pathway activation is commonly found in both $B R A F$ and NRAS mutant melanoma. AKT3 amplification and mRNA overexpression are frequent in $R A S$ mutant melanomas (around $40 \%$ of the cases), whereas PTEN mutations and deletions are enriched in BRAF mutant melanomas (around $20 \%$ of the cases). PIK3CA mutations have been observed in $3 \%$ of all melanomas. ${ }^{3}$ Combination PI3K or AKT inhibitors with MEK inhibitors has shown synergic growth inhibition in melanoma cell lines with activating NRAS mutations. ${ }^{47}$

Dual inhibition with alpelisib (a selective PI3K $\alpha$ inhibitor) and binimetinib has been assessed in a phase $\mathrm{Ib}$ trial enrolling 58 patients with BRAF or RAS mutated advanced solid tumors. Five patients with $N R A S$-mutant melanoma were enrolled achieving an ORR of $20 \%{ }^{48}$

The combination of pimasertib and voxtalisib (a dual $\mathrm{PI} 3 \mathrm{~K} / \mathrm{mTOR}$ inhibitor) was tested in a phase $\mathrm{Ib}$ trial including 146 patients. Twenty patients with BRAF V600mutant melanoma (progressing on BRAF inhibitors) were included ( 3 patients in escalation cohorts and 17 patients in disease specific expansion cohort). Response rate was $14 \%$ in the melanoma cohort ( 1 complete response and 1 PR). Absence of clinical efficacy and tolerability concerns led to premature trial termination. ${ }^{49}$

Trametinib combination with an AKT inhibitor (GSK2141795) has also been evaluated in a phase II clinical trial including 10 NRAS mutant patients with melanoma. No objective responses were observed and the PFS was 2.3 months. ${ }^{50}$ Even though preclinical evidence supported dual MAPK-PI3K/AKT/mTOR inhibition, clinical 
trials show absence of efficacy and poor drug combination tolerability.

\section{CDK4/6 Inhibitors - Cell Cycle}

Cell cycle is deregulated in BRAF and NRAS-mutant melanomas. NRAS mutant melanomas harbor $C D K N 2 A$ alterations (including mutation, deletion or promoter hypermethylation) and CCND1 amplifications in $70 \%$ and $10 \%$ of cases, respectively. ${ }^{3}$

Moreover, NRAS activation causes an increase on cyclin D1 expression which regulates cyclin-dependent kinase 4/6 (CDK 4/6) involved in G1/S cell-cycle checkpoint. $^{51}$

Based on these observations, combination of ribociclib (a CDK 4/6 inhibitor) and binimetinib has been evaluated in 63 NRAS mutant advanced or metastatic melanoma patients under a phase Ib/II trial. Results from the phase II dose expansion showed an ORR $19.5 \%(n=41)$ with a PFS of 3.7 months. ${ }^{52}$

Ongoing trial in NRAS mutant melanoma patients involving the combination of LXH254 (an RAF inhibitor) with LTT462 (an ERK 1/2 inhibitor), Trametinib or Ribociclib is still recruiting. ${ }^{53}$

\section{Epigenetics}

NRAS-mutant melanoma is more associated with $\mathrm{CpG}$ Island methylation pattern (CIMP) than $B R A F$-mutant melanoma. Mutations in the chromatin remodeler ARID2 gene and the epigenetic regulator IDH1 were also found in $16 \%$ and $9 \%$ of NRAS-mutant samples, respectively. ${ }^{3}$ Combination strategies with epigenetic modulators could increase efficacy of MEK inhibitors.

Data from de TCGA revealed that high BRD4 mRNA expression was associated with poor outcomes. Bromodomain and Extraterminal Domain (BET) proteins, such as BRD4, read acetylated lysine residues in histones and non-histone proteins promoting gene expression. In vitro (spheroids) and in vivo (xenografts) treatment combining JQ-1 (a BET inhibitor) and Mirdametinib (MEKi) decreased tumor growth rate and induced apoptosis in NRAS-mutant melanoma models. Efficacy was associated with downregulation of the TCF19 transcription factor and E2F1/3-dependent targets, involved in cell cycle $\mathrm{G} 1$ to $\mathrm{S}$ transition. ${ }^{54}$

\section{Tyrosine Kinase Inhibitors}

$N R A S$ melanoma cell lines, unlike $B R A F$-mutant melanoma, harbor constitutive phosphorylation of receptors with tyrosine kinase activity, such as Axl, ERBB2, c-MET or EGFR. ${ }^{55}$
However, activity of tyrosine kinase inhibitors have been examined in melanoma patients with limited benefit as monotherapy.

As an example, lenvatinib achieved an ORR of $9 \%$ and a mPFS 3.7 months in patients with BRAF wild type advanced melanomas. ${ }^{56}$ Axitinib yielded an ORR $18.8 \%$ and a 6-months PFS $33.9 \%$ in molecular unselected population. ${ }^{52}$ Patients were less pre-treated (maximum of 1 previous line) and only $25 \%$ of patients received immunotherapy in the axitinib trial compared to lenvatinib trial. ${ }^{56,57}$

Sorafenib and tivantinib (a MET inhibitor) combination have been evaluated in eight patients with NRASmutant melanoma. PR was objectified in two patients and another two stable disease (SD) as best response. ${ }^{58}$

Axitinib has been also combined with chemotherapy. Combination with Carboplatin/Paclitaxel ( $\mathrm{n}=38$ patients) increased ORR to $22 \%$ and PFS to 8.7 months in unselected population, with better outcomes for non-BRAF V600E/K population. Regarding NRAS-mutant patients $(\mathrm{n}=8), 2$ patients achieved PR and 6 patients SD as best response. ${ }^{59}$

Combination of TKI with MAPK or PI3K-AKT-mTOR inhibitors might decrease acquired resistance to targeted therapy and compensatory feedback of the intracellular pathway. ${ }^{60}$ Combination of pazopanib and trametinib has been performed under a phase I trial. Four patients with melanoma were enrolled, with SD as best response in 3 patients. Unfortunately, no information about $R A F / R A S$ status was given. ${ }^{61}$

\section{ERK Inhibitors}

ERK is the final kinase in the MAPK signaling pathway. Therefore, ERK inhibitors (ERKis) could be an interesting treatment target for $N R A S$-mutant melanoma patients. ${ }^{13,14}$ Preclinical data supports this concept.

SCH772984 has proved efficacy in NRAS, KRAS, and $B R A F$-mutant cell lines as in melanoma animal resistant to BRAF inhibitors. ${ }^{62}$ In NRAS-Q61H mutant cell line, ERK inhibition with VX-11e displayed greater proliferative arrest than MEKi. Treatment with MEKi did not suppressed ERKdependent phosphorylation of downstream targets. RTK activation and cross-talk of other signaling pathways with ERK pathway were the explanation. ${ }^{63}$

Ulixertinib is a reversible, ATP-competitive ERK1/2 inhibitor. Safety and preliminary efficacy have been assessed in a phase-I clinical trial enrolling patients with $N R A S$-mutant and $B R A F$-mutant melanomas. Preliminary results from one of the expansion cohorts for NRASmutant melanoma patients $(\mathrm{n}=19)$, not previously treated 
with BRAF and/or MEK inhibitors, showed PR in $13.5 \%$ and DCR in $52.6 \%$ of the patients. ${ }^{64,65}$

Further development of novel ERKi in phase I clinical trials as single agents or in combination with MEKis, chemotherapy or targeted agents are awaited.

Table 3 summarizes the efficacy outcomes of targeted therapies (monotherapy and combinations) in patients with $N R A S$-mutant melanoma.

\section{Future Strategies for NRAS-Mutant Melanoma \\ The KRAS Situation}

To date, targeting directly on GTP binding pocket in RAS protein has been difficult due to the strong affinity between GTP and RAS. ${ }^{18}$ Nevertheless, recently, a small molecule that specifically and irreversibly inhibits KRAS G12C (AMG 510 or Sotorasib) has shown antitumor activity in patients with KRAS G12C-mutant advanced solid tumors. ${ }^{66}$

Sotorasib forms an irreversible covalent bond to the sulfur atom in the cysteine residue that is present in the mutated form of KRAS G12C, but not in the normal form. The inhibitor traps KRAS G12C in the inactive GDPbound state, inhibiting its phosphorylation activity. ${ }^{67}$

New RAS targeting strategies still need further development. For example, instead of targeting RAS protein activity we could block protein translation by RNA interference. Challenges regarding RNA delivery, intravascular degradation, intracellular trafficking, and potential off target effects are delaying its clinical implementation. ${ }^{68}$

Table 3 Summary of Efficacy Outcomes of Targeted Therapies (Monotherapy and Combinations) in Patients with NRAS-Mutant Melanoma. "Sample Size" Refers to Number of Patients Included with NRAS-Mutant Melanoma in the Clinical Trial

\begin{tabular}{|c|c|c|c|c|c|}
\hline Drug/s & Trial & Target Population & $\begin{array}{l}\text { Sample } \\
\text { Size }\end{array}$ & Efficacy Outcomes & Reference \\
\hline Trametinib & Phase II & Melanoma & $n=7$ & ORR $=0 \%$ with $29 \%$ of SD ( $2 / 7$ patients) & [37] \\
\hline Binimetinib & $\begin{array}{l}\text { Phase III vs } \\
\text { Dacarbazine }\end{array}$ & NRASmt melanoma & $n=402$ & $\begin{array}{l}\text { Binimetinib increased ORR ( } 15 \% \text { vs } 7 \% \text { ) and PFS ( } 2.8 \\
\text { vs I.5 months; HR } 0.62) \text {. } \\
\text { No OS differences (II vs I0.I months; HR I.00). }\end{array}$ & [39] \\
\hline Pimasertib & $\begin{array}{l}\text { Phase II vs } \\
\text { Dacarbazine }\end{array}$ & NRASmt melanoma & $n=194$ & $\begin{array}{l}\text { Pimasertib increased DCR ( } 37.7 \% \text { vs } 26.6 \%) \text { and PFS } \\
\text { ( } 13 \text { vs } 6.9 \text { weeks). No OS differences ( } 8.9 \text { vs } 10.6 \\
\text { months). }\end{array}$ & [40] \\
\hline $\begin{array}{l}\text { RO4987655 } \\
\text { (MEKi) }\end{array}$ & Phase I & $\begin{array}{l}\text { KRASmt NSCLC and } \\
\text { CRC, BRAFmt and wt } \\
\text { melanoma }\end{array}$ & $n=8$ & ORR $=13 \%$ with $D C R=39 \%$ & [4I] \\
\hline $\begin{array}{l}\text { Alpelisib + } \\
\text { Binimetinib }\end{array}$ & Phase lb & $\begin{array}{c}\text { BRAFmt or RASmt solid } \\
\text { tumors }\end{array}$ & $n=5$ & $O R R=20 \%$ & [48] \\
\hline $\begin{array}{l}\text { GSK2I } 41795 \\
\text { (AKT inhibitor) + } \\
\text { Trametinib }\end{array}$ & Phase II & $\begin{array}{l}\text { NRASmt and BRAFI } \\
\text { NRASwt melanoma }\end{array}$ & $n=10$ & ORR $0 \%$ and PFS 2.3 months. & [50] \\
\hline $\begin{array}{l}\text { Ribociclib + } \\
\text { Binimetinib }\end{array}$ & Phase Ib/II & NRASmt melanoma & $n=4 I$ & ORR $19.5 \%$ and PFS 3.7 months. & [52] \\
\hline $\begin{array}{l}\text { Sorafenib + } \\
\text { Tivatinib }\end{array}$ & Phase I & $\begin{array}{l}\text { NRASmt or wt } \\
\text { melanoma }\end{array}$ & $n=8$ & ORR $=25 \%$ with $D C R=50 \%$ & [58] \\
\hline $\begin{array}{l}\text { Axitinib }+ \\
\text { Carboplatin/ } \\
\text { Paclitaxel }\end{array}$ & Phase II & Melanoma & $n=8$ & ORR $=25 \%$ with $D C R=100 \%$ & [59] \\
\hline Ulixertinib & Phase I & $\begin{array}{c}\text { NRASmt or BRAFmt } \\
\text { melanoma }\end{array}$ & $n=19$ & ORR $=13.5 \%$ with $D C R=52.6 \%$ & [65] \\
\hline
\end{tabular}

Abbreviations: ORR, overall response rate; DCR, disease control rate; PFS, progression free survival; OS, overall survival; Mt, mutant; Wt, wild type. 


\section{NFI}

NF1 (neurofibromin 1) acts as a tumor suppressor through GAP activity which turns the active RAS-GTP to RASGDP ${ }^{69}$ Calpain 1 (CAPN1) is a calcium-dependent neutral cysteine protease that regulates NF1 degradation in melanoma cell lines. ${ }^{70}$

Combination of Calpain 1 inhibitor with Trametinib added antiproliferative activity in terms of cell growth reduction compared to Trametinib alone in melanoma cell lines. ${ }^{70}$ This combination may increase MEK inhibitors' efficacy in NRAS-mutant melanoma in the future.

\section{PPP6C}

PPP6C (Protein Phosphatase 6 Catalytic Subunit) encodes a Serine/Threonine phosphatase involved in cell cycle regulation and progression. ${ }^{71}$ Among the different substrates of PPP6C we find $\mathrm{MEK}^{72}$ and Aurora-A. ${ }^{73}$

Loss of PPP6C promotes MEK hyperphosphorylation (at activating and crosstalk phosphorylation sites) inducing ERK pathway signaling and resistance to MEK inhibitors in vitro. ${ }^{72}$

Loss of its activity is also linked to elevated Aurora-A kinase activity, leading to mis-segregation of chromosomes during mitosis leading to chromosome instability. Aurora-A inhibitors may be a treatment strategy to treat melanomas harboring PPP6C inactivation. ${ }^{73}$

\section{STKI9}

STK19 (serine threonine kinase 19) is a serine/threonine kinase which regulates NRAS signaling. ${ }^{74}$ It phosphorylates NRAS S89 residue, activating its signaling via the MAPK and PI3K pathways in human melanocyte cell lines. ${ }^{74,75}$ STK19 activating mutations are mutually exclusive with BRAF in melanoma. ${ }^{75}$

In NRAS Q61R transgenic mice, the STK19 D89N mutant promoted oncogenic NRAS driven melanomagenesis. ZT-12-037-01 (an STK19 inhibitor) reduced cell division and induced apoptosis in NRAS-STK19 mutant mice xenografts. ${ }^{75}$ Consistent with these observations, STK19 inhibition could be a potential therapeutic strategy for $N R A S$-mutant melanoma.

\section{PTPNII}

PTPN11 (protein tyrosine phosphatase non-receptor type 11) gene encodes $\mathrm{SH} 2$, a phosphatase which contains two tandem Src homology-2 domains which interact with phospho-tyrosines in transmembrane cellular receptors. SHP2 activity is involved in RAS signaling activation. $^{76}$

Activating mutations of PTPN11 appear to be oncogenic in melanoma. Conversely, SHP2 inhibitor SHP099 promotes antitumoral response of NRAS Q61K-mutant melanomas in mice models. ${ }^{77}$

\section{OTHER}

Other targets not directly related to RAS signaling which have shown early preclinical evidence in combination with MEKi involve inhibition of the ROCK 1/2 (GTPaseactivated serine/threonine kinases), ${ }^{78}$ ER (estrogen receptor) ${ }^{79}$ or HSP90 (Heat shock protein-90). ${ }^{80}$

\section{Clinical Trials Ongoing}

Table 4 summarizes ongoing clinical trials with potential beneficial treatment strategies recruiting patients with $N R A S$-mutant melanoma either as the main target population or included in unselected solid tumor cohort.

\section{Conclusion}

NRAS-mutant melanoma constitutes around $15-20 \%$ of patients with melanoma and is known to be associated with poorer prognosis.

Clinical trial experience over the last years with different MEK inhibitors have shown limited efficacy in monotherapy. Treatment strategies in the near future will include combination of MEK inhibitors with inhibitors of the main intracellular pathways (either involved in RAS signaling or not) or other drugs disrupting cell-cycle checkpoints or epigenetics. Currently, little effort has been done towards mutant NRAS specific treatment, either with direct inhibitors or post-traductional interactions.

To date, checkpoint inhibitors seem to be as effective or even more effective in patients with NRAS-mutant melanoma compared to distinct melanoma subtypes. 
Table 4 Ongoing Clinical Trials Recruiting Patients with NRAS-Mutant Melanoma

\begin{tabular}{|c|c|c|c|c|c|c|}
\hline $\begin{array}{l}\text { Clinicaltrials. } \\
\text { gov } \\
\text { Identifier }\end{array}$ & Title & Phase & $\mathbf{N}$ & Population & $\begin{array}{c}\text { Treatment } \\
\text { Arms }\end{array}$ & Primary Endpoint \\
\hline NСT0194I927 & $\begin{array}{l}\text { Phase II Clinical Trial of the } \\
\text { MEK Inhibitor Trametinib } \\
\text { With the AKT Inhibitor } \\
\text { GSK2I4I795 in BRAF Wild- } \\
\text { type Melanoma. }\end{array}$ & ॥ & 20 & $\begin{array}{l}\text { Unresectable Stage III or Stage } \\
\text { IV disease. Evidence of tumor } \\
\text { DNA showing either NRAS } \\
\text { mutation or NRAS Wild-Type } \\
\text { (WT)/BRAF WT. }\end{array}$ & $\begin{array}{l}\text { Arm A: Trametinib } \\
\text { (GSKII } 202 \mid 2) \\
2 \mathrm{mg} \text { daily oral + } \\
\text { GSK2। } 4 \mid 795 \\
25 \mathrm{mg} \text { daily oral. }\end{array}$ & ORR \\
\hline NCT02974725 & $\begin{array}{l}\text { A Phase lb, Open-label, } \\
\text { Multicenter Study of Oral } \\
\text { LXH254-centric } \\
\text { Combinations in Adult } \\
\text { Patients With Advanced or } \\
\text { Metastatic KRAS or BRAF } \\
\text { Mutant Non-Small Cell Lung } \\
\text { Cancer or NRAS Mutant } \\
\text { Melanoma }\end{array}$ & $\mathrm{lb}$ & 315 & $\begin{array}{l}\text { Patients with advanced or } \\
\text { metastatic NSCLC or } \\
\text { cutaneous melanoma. } \\
\text { Presence of KRAS or BRAF } \\
\text { mutation (NSCLC) or NRAS } \\
\text { mutation (cutaneous } \\
\text { melanoma) in tumor tissue. }\end{array}$ & $\begin{array}{l}\text { Arm A: LXH254 + } \\
\text { LTT462. } \\
\text { Arm B: LXH254 + } \\
\text { Trametinib. } \\
\text { Arm C: LXH254 + } \\
\text { Ribociclib. }\end{array}$ & $\begin{array}{l}\text { Number of } \\
\text { participants with AEs } \\
\text { and experiencing } \\
\text { DLTs. } \\
\text { Tolerability measured } \\
\text { by the number of } \\
\text { subjects who have } \\
\text { interruptions/ } \\
\text { reductions of study } \\
\text { treatment and } \\
\text { by the dose intensity } \\
\text { of study drug. }\end{array}$ \\
\hline NCT03634982 & $\begin{array}{l}\text { A Phase I, Open-Label, } \\
\text { Multicenter, Dose-Escalation } \\
\text { Study of RMC-4630 } \\
\text { Monotherapy in Adult } \\
\text { Participants With Relapsed/ } \\
\text { Refractory Solid Tumors }\end{array}$ & I & 210 & $\begin{array}{l}\text { Advanced solid tumors that } \\
\text { have failed, are intolerant to, } \\
\text { or are considered ineligible } \\
\text { for standard of care anticancer } \\
\text { treatments. }\end{array}$ & $\begin{array}{l}\text { RMC-4630 (SHP2 } \\
\text { inhibitor) }\end{array}$ & $\begin{array}{l}\text { Number of } \\
\text { participants with AEs } \\
\text { and experiencing } \\
\text { DLTs. }\end{array}$ \\
\hline NCT0397965I & $\begin{array}{l}\text { MEK and Autophagy Inhibition } \\
\text { in Metastatic/Locally } \\
\text { Advanced, Unresectable NRAS } \\
\text { Melanoma: A Phase Ib/ll Trial } \\
\text { of Trametinib Plus } \\
\text { Hydroxychloroquine in } \\
\text { Patients With NRAS } \\
\text { Melanoma }\end{array}$ & $\mathrm{lb} / \mathrm{Il}$ & 29 & $\begin{array}{l}\text { Patients with histologically } \\
\text { confirmed metastatic or } \\
\text { locally advanced unresectable } \\
\text { malignant melanoma with an } \\
\text { activating NRAS mutation } \\
\text { progressing during or after } \\
\text { a first line treatment by } \\
\text { immunotherapy. }\end{array}$ & $\begin{array}{l}\text { Trametinib + } \\
\text { Hidroxicloroquine } \\
\text { ( } 3 \text { different dose } \\
\text { scalation cohorts) }\end{array}$ & $\begin{array}{l}\text { Number of } \\
\text { participants with AEs } \\
\text { and ORR. }\end{array}$ \\
\hline NCT03973I5I & $\begin{array}{l}\text { A Phase I/II, Single Arm, Dose } \\
\text { Escalation and Cohort } \\
\text { Expansion Study to Evaluate } \\
\text { Safety, Preliminary Efficacy of } \\
\text { HL-085 in Patients With NRAS } \\
\text { Mutant Advanced Melanoma. }\end{array}$ & $\mathrm{I} / \mathrm{II}$ & 54 & $\begin{array}{l}\text { Patients with histologically or } \\
\text { cytologically confirmed } \\
\text { unresectable Stage III or Stage } \\
\text { IV melanoma according to } \\
\text { AJCC (Version 7, 20I0) and } \\
\text { NRAS mutation. }\end{array}$ & $\begin{array}{l}\text { HL-085 (MEK } \\
\text { inhibitor) }\end{array}$ & $\begin{array}{l}\text { Number of } \\
\text { participants with AEs } \\
\text { and the MTD. }\end{array}$ \\
\hline NCT03932253 & $\begin{array}{l}\text { A Phase la/lb Clinical Study to } \\
\text { Evaluate the Safety, } \\
\text { Pharmacokinetics (PK) and } \\
\text { Preliminary Anti-tumor } \\
\text { Activity of FCN-159 in } \\
\text { Patients With Advanced } \\
\text { Melanoma Harboring NRAS- } \\
\text { aberrant (la) and NRAS-mutant } \\
\text { (lb) }\end{array}$ & $\mathrm{la} / \mathrm{lb}$ & 37 & $\begin{array}{l}\text { Patients with histologically or } \\
\text { cytologically diagnosed } \\
\text { advanced melanoma who } \\
\text { cannot be surgically resected, } \\
\text { stage III or IV, and have failed } \\
\text { or rejected standard } \\
\text { treatment with NRAS } \\
\text { aberration (Phase la) or NRAS } \\
\text { mutation (Phase lb). }\end{array}$ & $\begin{array}{l}\text { FCN-I59 (MEK } \\
\text { inhibitor) }\end{array}$ & $\begin{array}{l}\text { Number of } \\
\text { participants with AEs, } \\
\text { the MTD and ORR. }\end{array}$ \\
\hline
\end{tabular}

(Continued) 
Table 4 (Continued).

\begin{tabular}{|l|l|c|c|l|l|l|}
\hline $\begin{array}{l}\text { Clinicaltrials. } \\
\text { gov } \\
\text { Identifier }\end{array}$ & \multicolumn{1}{|c|}{ Title } & Phase & N & \multicolumn{1}{|c|}{ Population } & \multicolumn{1}{c|}{$\begin{array}{l}\text { Treatment } \\
\text { Arms }\end{array}$} & Primary Endpoint \\
\hline NCT04I09456 & $\begin{array}{l}\text { A Phase Ib, Open-label Clinical } \\
\text { Study to Evaluate the Safety, } \\
\text { Tolerability, Pharmacokinetics } \\
\text { and Antitumor Activities of } \\
\text { INI00I8 as Monotherapy and } \\
\text { Combination Therapy in } \\
\text { Subjects With Metastatic } \\
\text { Melanoma. }\end{array}$ & lb & 52 & $\begin{array}{l}\text { Patients with histologically or } \\
\text { cytologically confirmed } \\
\text { metastatic uveal melanoma or } \\
\text { metastatic NRAS-mutant } \\
\text { melanoma. }\end{array}$ & $\begin{array}{l}\text { Part A: INI00I8 } \\
\text { (FAK inhibitor). } \\
\text { Part B: INI00I8 + }\end{array}$ & $\begin{array}{l}\text { Cobimetinib. } \\
\text { of INI00I8 } \\
\text { monotherapy and in } \\
\text { combination with } \\
\text { Cobimetinib. }\end{array}$ \\
\hline
\end{tabular}

Abbreviations: ORR, overall response rate; AEs, adverse events; DLT, dose limiting toxicities; MTD, maximum tolerated dose; WT, wild type.

\section{Disclosure}

The authors reported no conflicts of interest for this work.

\section{References}

1. Global cancer statistics 2020: GLOBOCAN. Available from: https:// gco.iarc.fr. Accessed June 7, 2021.

2. Cancer Council. Skin cancer incidence and mortality. Available from: https://wiki.cancer.org.au/skincancerstats/Skin_cancer_incidence and_mortality. Accessed June 7, 2021.

3. Cancer Genome Atlas Network. Genomic classification of cutaneous melanoma. Cell. 2015;161(7):1681-1696. doi:10.1016/j. cell.2015.05.044.

4. Ascierto PA, McArthur GA, Dréno B, et al. Cobimetinib combined with vemurafenib in advanced BRAF(V600)-mutant melanoma (coBRIM): updated efficacy results from a randomised, double-blind, Phase 3 trial. Lancet Oncol. 2016;17(9):1248-1260.

5. Robert C, Grob JJ, Stroyakovskiy D, et al. Five-year outcomes with dabrafenib plus trametinib in metastatic melanoma. $N$ Engl J Med. 2019;381(7):626-636. doi:10.1056/NEJMoa1904059

6. Dummer R, Ascierto PA, Gogas HJ, et al. Overall survival in patients with BRAF-mutant melanoma receiving encorafenib plus binimetinib versus vemurafenib or encorafenib (COLUMBUS): a multicentre, open-label, randomised, phase 3 trial. Lancet Oncol. 2018;19 (10):1315-1327. doi:10.1016/S1470-2045(18)30497-2

7. Hodi FS, O'Day SJ, McDermott DF, et al. Improved survival with ipilimumab in patients with metastatic melanoma. $N$ Engl $\mathrm{J} \mathrm{Med}$. 2010;363(8):711-723. doi:10.1056/NEJMoa1003466

8. Robert C, Long GV, Brady B, et al. Nivolumab in previously untreated melanoma without BRAF mutation. $N$ Engl J Med. 2015;372(4):320-330. doi:10.1056/NEJMoa1412082

9. Robert C, Schachter J, Long GV, et al. Pembrolizumab versus ipilimumab in advanced melanoma. $N$ Engl $J$ Med. 2015;372 (26):2521-2532. doi:10.1056/NEJMoa1503093

10. Larkin J, Chiarion-Sileni V, Gonzalez R, et al. Combined nivolumab and ipilimumab or monotherapy in untreated melanoma. $N$ Engl $J$ Med. 2015;373(1):23-34. doi:10.1056/NEJMoa1504030

11. Devitt B, Liu W, Salemi R, et al. Clinical outcome and pathological features associated with NRAS mutation in cutaneous melanoma. Pigment Cell Melanoma Res. 2011;24(4):666-672. doi:10.1111/ j.1755-148X.2011.00873.x

12. Thumar J, Shahbazian D, Aziz SA, Jilaveanu LB, Kluger HM. MEK targeting in N-RAS mutated metastatic melanoma. Mol Cancer. 2014;13:45. doi:10.1186/1476-4598-13-45
13. Malumbres M, Barbacid M. RAS oncogenes: the first 30 years. Nat Rev Cancer. 2003;3(6):459-465. doi:10.1038/nrc1097

14. Mendoza MC, Er EE, Blenis J. The Ras-ERK and PI3K-mTOR pathways: cross-talk and compensation. Trends Biochem Sci. 2011;36(6):320-328. doi:10.1016/j.tibs.2011.03.006

15. Moore AR, Rosenberg SC, McCormick F, et al. RAS-targeted therapies: is the undruggable drugged? Nat Rev Drug Discov. 2020;19 (8):533-552. doi:10.1038/s41573-020-0068-6

16. Albino AP, Le Strange R, Oliff AI, Furth ME, Old LJ. Transforming ras genes from human melanoma: a manifestation of tumour heterogeneity? Nature. 1984;308(5954):69-72. doi:10.1038/308069a0

17. Fedorenko IV, Gibney GT, Smalley KS. NRAS mutant melanoma: biological behavior and future strategies for therapeutic management. Oncogene. 2013;32(25):3009-3018. doi:10.1038/onc.2012.453

18. Simanshu DK, Nissley DV, McCormick F. RAS proteins and their regulators in human disease. Cell. 2017;170(1):17-33. doi:10.1016/j. cell.2017.06.009

19. Hodis E, Watson IR, Kryukov GV, et al. A landscape of driver mutations in melanoma. Cell. 2012;150(2):251-263. doi:10.1016/j. cell.2012.06.024

20. Ellerhorst JA, Greene VR, Ekmekcioglu S, et al. Clinical correlates of NRAS and BRAF mutations in primary human melanoma. Clin Cancer Res. 2011;17(2):229-235. doi:10.1158/1078-0432.CCR-10-2276

21. Jakob JA, Bassett RL Jr, Ng CS, et al. NRAS mutation status is an independent prognostic factor in metastatic melanoma. Cancer. 2012;118(16):4014-4023. doi:10.1002/cncr.26724

22. Adler NR, Wolfe R, Kelly JW, et al. Tumour mutation status and sites of metastasis in patients with cutaneous melanoma. Br J Cancer. 2017;117(7):1026-1035. doi:10.1038/bjc.2017.254

23. Michielin O, van Akkooi A, Ascierto P, et al. Cutaneous melanoma: ESMO Clinical Practice Guidelines for diagnosis, treatment and follow-up. Ann Oncol. 2019;30:1884-1901.

24. Kirchberger MC, Ugurel S, Mangana J, et al. MEK inhibition may increase survival of NRAS-mutated melanoma patients treated with checkpoint blockade: results of a retrospective multicentre analysis of 364 patients. Eur J Cancer. 2018;98:10-16. doi:10.1016/j. ejca.2018.04.010

25. Guida M, Bartolomeo N, Quaglino P, et al. No Impact of NRAS mutation on features of primary and metastatic melanoma or on outcomes of checkpoint inhibitor immunotherapy: an Italian Melanoma Intergroup (IMI) study. Cancers (Basel). 2021;13(3):475. doi:10.3390/cancers 13030475

26. Johnson DB, Lovly CM, Flavin M, et al. Impact of NRAS mutations for patients with advanced melanoma treated with immune therapies. Cancer Immunol Res. 2015;3(3):288-295. doi:10.1158/2326-6066. CIR-14-0207 
27. Rose AAN, Armstrong SM, Hogg D, et al. Biologic subtypes of melanoma predict survival benefit of combination anti-PD1+antiCTLA4 immune checkpoint inhibitors versus anti-PD1 monotherapy. J Immunother Cancer. 2021;9(1):e01642. doi:10.1136/jitc-2020-001642

28. Ahearn IM, Haigis K, Bar-Sagi D, et al. Regulating the regulator: post-translational modification of RAS. Nat Rev Mol Cell Biol. 2011;13(1):39-51. doi:10.1038/nrm3255

29. Smalley KS, Eisen TG. Farnesyl transferase inhibitor SCH66336 is cytostatic, pro-apoptotic and enhances chemosensitivity to cisplatin in melanoma cells. Int J Cancer. 2003;105(2):165-175. doi:10.1002/ ijc. 11064

30. Niessner H, Beck D, Sinnberg T, et al. The farnesyl transferase inhibitor lonafarnib inhibits mTOR signaling and enforces sorafenib-induced apoptosis in melanoma cells. $J$ Invest Dermatol. 2011;131(2):468-479. doi:10.1038/jid.2010.297

31. Chow LQ, Eckhardt SG, O'Bryant CL, et al. A phase I safety, pharmacological, and biological study of the farnesyl protein transferase inhibitor, lonafarnib ( $\mathrm{SCH}$ 663366), in combination with cisplatin and gemcitabine in patients with advanced solid tumors. Cancer Chemother Pharmacol. 2008;62(4):631-646. doi:10.1007/ s00280-007-0646-x

32. Margolin KA, Moon J, Flaherty LE, et al. Randomized phase II trial of sorafenib with temsirolimus or tipifarnib in untreated metastatic melanoma (S0438). Clin Cancer Res. 2012;18(4):1129-1137. doi:10.1158/1078-0432.CCR-11-2488

33. Gajewski TF, Salama AK, Niedzwiecki D, et al. Phase II study of the farnesyltransferase inhibitor R115777 in advanced melanoma (CALGB 500104). J Transl Med. 2012;10:246. doi:10.1186/14795876-10-246

34. Whyte DB, Kirschmeier P, Hockenberry TN, et al. K- and N-Ras are geranylgeranylated in cells treated with farnesyl protein transferase inhibitors. J Biol Chem. 1997;272(22):14459-14464. doi:10.1074/ jbc.272.22.14459

35. Brock EJ, Ji K, Reiners JJ, Mattingly RR. How to target activated ras proteins: direct inhibition vs. induced mislocalization. Mini Rev Med Chem. 2016;16(5):358-369. doi:10.2174/ 1389557515666151001154002

36. Cheng Y, Tian H. Current development status of MEK inhibitors. Molecules. 2017;22:1551. doi:10.3390/molecules22101551

37. Falchook GS, Lewis KD, Infante JR, et al. Activity of the oral MEK inhibitor trametinib in patients with advanced melanoma: a Phase 1 dose-escalation trial. Lancet Oncol. 2012;13(8):782-789. doi:10.1016/S1470-2045(12)70269-3

38. Ascierto PA, Schadendorf D, Berking C, et al. MEK162 for patients with advanced melanoma harbouring NRAS or Val600 BRAF mutations: a non-randomised, open-label Phase 2 study. Lancet Oncol. 2013;14(3):249-256. doi:10.1016/S1470-2045(13)70024-X

39. Dummer R, Schadendorf D, Ascierto PA, et al. Binimetinib versus dacarbazine in patients with advanced NRAS-mutant melanoma (NEMO): a multicentre, open-label, randomised, phase 3 trial. Lancet Oncol. 2017;18(4):435-445. doi:10.1016/S1470-2045(17) 30180-8

40. Lebbé C, Dutriaux C, Lesimple T, et al. Pimasertib versus dacarbazine in patients with unresectable NRAS-mutated cutaneous melanoma: Phase II, randomized, controlled trial with crossover. Cancers (Basel). 2020;12(7):1727. doi:10.3390/cancers12071727

41. Zimmer L, Barlesi F, Martinez-Garcia M, et al. Phase I expansion and pharmacodynamic study of the oral MEK inhibitor RO4987655 (CH4987655) in selected patients with advanced cancer with RAS-RAF mutations. Clin Cancer Res. 2014;20(16):4251-4261. doi:10.1158/1078-0432.CCR-14-0341

42. Dorard C, Estrada C, Barbotin C, et al. RAF proteins exert both specific and compensatory functions during tumour progression of NRAS-driven melanoma. Nat Commun. 2017;12:15262. doi:10.1038/ ncomms 15262
43. Heidorn SJ, Milagre C, Whittaker S, et al. Kinase-dead BRAF and oncogenic RAS cooperate to drive tumor progression through CRAF. Cell. 2010;140(2):209-221.

44. Sullivan RJ, Hollebecque A, Flaherty KT, et al. A Phase I Study of LY3009120, a Pan-RAF inhibitor, in patients with advanced or metastatic cancer. Mol Cancer Ther. 2020;19(2):460-467. doi:10.1158/ 1535-7163

45. Kim TW, Lee J, Shin SJ, et al. Belvarafenib, a novel pan-RAF inhibitor, in solid tumor patients harboring BRAF, KRAS, or NRAS mutations: phase I study. JCO. 2019;37:3000. doi:10.1200/ JCO.2019.37.15_suppl.3000

46. Atefi M, Titz B, Avramis E, et al. Combination of pan-RAF and MEK inhibitors in NRAS mutant melanoma. Mol Cancer. 2015;14(1):27. doi:10.1186/s12943-015-0293-5

47. Greger JG, Eastman SD, Zhang V, et al. Combinations of BRAF, $\mathrm{MEK}$, and $\mathrm{PI} 3 \mathrm{~K} / \mathrm{mTOR}$ inhibitors overcome acquired resistance to the BRAF inhibitor GSK2118436 dabrafenib, mediated by NRAS or MEK mutations. Mol Cancer Ther. 2012;11(4):909-920. doi:10.1158/1535-7163.MCT-11-0989

48. Juric D, Soria JC, Sharma S, et al. A phase $1 \mathrm{~b}$ dose-escalation study of by1719 plus binimetinib (MEK162) in patients with selected advanced solid tumors. J Clin Oncol. 2014;32(15):9051. doi:10.1200/jco.2014.32.15_suppl.9051

49. Schram AM, Gandhi L, Mita MM, et al. A phase Ib dose-escalation and expansion study of the oral MEK inhibitor pimasertib and PI3K/ MTOR inhibitor voxtalisib in patients with advanced solid tumours. Br J Cancer. 2018;119(12):1471-1476. doi:10.1038/s41416-0180322-4

50. Algazi AP, Esteve-Puig R, Nosrati A, et al. Dual MEK/AKT inhibition with trametinib and GSK2141795 does not yield clinical benefit in metastatic NRAS-mutant and wild-type melanoma. Pigment Cell Melanoma Res. 2018;31(1):110-114. doi:10.1111/pcmr.12644

51. Eskandarpour M, Huang F, Reeves KA, et al. Oncogenic NRAS has multiple effects on the malignant phenotype of human melanoma cells cultured in vitro. Int $J$ Cancer. 2009;124(1):16-26. doi:10.1002/ijc. 23876

52. ClinicalTrials.gov. A Phase Ib/II Study of LEE011 in combination with MEK162 in patients with NRAS mutant melanoma (NCT01781572). https://clinicaltrials.gov/ct2/show/NCT01781572. Accessed June 7, 2021.

53. ClinicalTrials.gov. A Phase Ib Study of LXH254-centric Combinations in NSCLC or Melanoma (NCT02974725). https://clin icaltrials.gov/ct2/show/NCT02974725. Accessed June 7, 2021.

54. Echevarría-Vargas IM, Reyes-Uribe PI, Guterres AN, et al. Cotargeting BET and MEK as salvage therapy for MAPK and checkpoint inhibitor-resistant melanoma. EMBO Mol Med. 2018;10(5): e8446. doi:10.15252/emmm.201708446

55. Fedorenko IV, Fang B, Koomen JM, et al. Amuvatinib has cytotoxic effects against NRAS-mutant melanoma but not BRAF-mutant melanoma. Melanoma Res. 2014;24(5):448-453. doi:10.1097/ CMR.0000000000000103

56. O'Day S, Gonzalez R, Kim K, et al. A phase II study of the multitargeted kinase inhibitor lenvatinib in patients with advanced BRAF wild-type melanoma. J Clin Oncol. 2013;31(15_suppl):9026. doi:10.1200/jco.2013.31.15_suppl.9026

57. Fruehauf J, Lutzky J, McDermott D, et al. Multicenter, phase II study of axitinib, a selective second-generation inhibitor of vascular endothelial growth factor receptors 1,2 , and 3 , in patients with metastatic melanoma. Clin Cancer Res. 2011;17(23):7462-7469. doi:10.1158/1078-0432.CCR-11-0534

58. Means-Powell JA, Adjei AA, Puzanov I, et al. Safety and efficacy of MET inhibitor tivantinib (ARQ 197) combined with sorafenib in patients (pts) with NRAS wild-type or mutant melanoma from a phase I study. J Clin Oncol. 2012;30:8519. doi:10.1200/ jco.2012.30.15_suppl.8519 
59. Algazi AP, Cha E, Ortiz-Urda SM, et al. The combination of axitinib followed by paclitaxel/carboplatin yields extended survival in advanced BRAF wild-type melanoma: results of a clinical/correlative prospective phase II clinical trial. $B r \quad J$ Cancer. 2015;112 (8):1326-1331. doi:10.1038/bjc.2014.541

60. Lee S, Rauch J, Kolch W. Targeting MAPK signaling in cancer: mechanisms of drug resistance and sensitivity. Int $\mathrm{J} \mathrm{Mol} \mathrm{Sci}$. 2020;21:1102. doi:10.3390/ijms21031102

61. Kurzrock R, Ball DW, Zahurak ML, et al. A Phase I Trial of the VEGF receptor tyrosine kinase inhibitor pazopanib in combination with the MEK inhibitor trametinib in advanced solid tumors and differentiated thyroid cancers. Clin Cancer Res. 2019;25 (18):5475-5484. doi:10.1158/1078-0432.CCR-18-1881

62. Morris EJ, Jha S, Restaino CR, et al. Discovery of a novel ERK inhibitor with activity in models of acquired resistance to BRAF and MEK inhibitors. Cancer Discov. 2013;3(7):742-750. doi:10.1158/ 2159-8290.CD-13-0070

63. Carlino MS, Todd JR, Gowrishankar K, et al. Differential activity of MEK and ERK inhibitors in BRAF inhibitor resistant melanoma. Mol Oncol. 2014;8(3):544-554. doi:10.1016/j.molonc.2014.01.003

64. Mendzelevski B, Ferber G, Janku F, et al. Effect of ulixertinib, a novel ERK1/2 inhibitor, on the QT/QTc interval in patients with advanced solid tumor malignancies. Cancer Chemother Pharmacol. 2018;81(6):1129-1141. doi:10.1007/s00280-018-3564-1

65. ClinicalTrials.gov. Phase I dose-escalation, safety, pharmacokinetic and pharmacodynamic study of BVD-523 in patients with advanced malignancies (NCT01781429). https://clinicaltrials.gov/ct2/show/ NCT01781429. Accessed June 7, 2021.

66. Hong DS, Fakih MG, Strickler JH, et al. KRASG12C Inhibition with Sotorasib in Advanced Solid Tumors. N Engl J Med. 2020;383 (13):1207-1217. doi:10.1056/NEJMoa1917239

67. Lito P, Solomon M, Li LS, et al. Allele-specific inhibitors inactivate mutant KRAS G12C by a trapping mechanism. Science. 2016;351 (6273):604-608. doi:10.1126/science.aad6204

68. Pecot CV, Calin GA, Coleman RL, et al. RNA interference in the clinic: challenges and future directions. Nat Rev Cancer. 2011;11 (1):59-67. doi:10.1038/nrc2966

69. Trovó-Marqui AB, Tajara EH. Neurofibromin: a general outlook. Clin Genet. 2006;70(1):1-13. doi:10.1111/j.1399-0004.2006.00639.x
70. Alon M, Arafeh R, Lee JS, et al. CAPN1 is a novel binding partner and regulator of the tumor suppressor NF1 in melanoma. Oncotarget. 2018;9(58):31264-31277. doi:10.18632/oncotarget.25805

71. UniProt Protein Knowledgebase (UniProtKB). PPP6C. Available from: https:/www.uniprot.org/uniprot/Q9CQR6. Accessed June 7, 2021 .

72. Cho E, Jane Lou H, Kuruvilla L, et al. PPP6C negatively regulates oncogenic ERK signaling through dephosphorylation of MEK. doi:10.1101/2020.09.18.303859

73. Hammond D, Zeng K, Espert A, et al. Melanoma-associated mutations in protein phosphatase 6 cause chromosome instability and DNA damage owing to dysregulated Aurora-A. J Cell Sci. 2013;126(Pt 15):3429-3440. doi:10.1242/jcs.128397

74. Asquith CRM, Temme L. STK19: a new target for NRAS-driven cancer. Nat Rev Drug Discov. 2020;19(9):579. doi:10.1038/d41573020-00116-x

75. Yin C, Zhu B, Zhang T, et al. Pharmacological targeting of STK19 inhibits oncogenic NRAS-driven melanomagenesis. Cell. 2019;176 (5):1113-1127.e16. doi:10.1016/j.cell.2019.01.002

76. Gene Cards. The Human Gene Database. PTPN11 Gene. Available from: https://www.genecards.org/cgi-bin/carddisp.pl?gene=PTPN11. Accessed June 7, 2021.

77. Hill KS, Roberts ER, Wang X, et al. PTPN11 plays oncogenic roles and is a therapeutic target for BRAF wild-type melanomas. Mol Cancer Res. 2019;17(2):583-593. doi:10.1158/1541-7786.MCR-180777

78. Vogel CJ, Smit MA, Maddalo G, et al. Cooperative induction of apoptosis in NRAS mutant melanoma by inhibition of MEK and ROCK. Pigment Cell Melanoma Res. 2015;28(3):307-317. doi:10.1111/pcmr.12364

79. Marzagalli M, Montagnani Marelli M, Casati L, et al. Estrogen Receptor $\beta$ in melanoma: from molecular insights to potential clinical utility. Front Endocrinol (Lausanne). 2016;7:140. doi:10.3389/ fendo.2016.00140

80. Haarberg HE, Paraiso KH, Wood E, et al. Inhibition of Wee1, AKT, and CDK4 underlies the efficacy of the HSP90 inhibitor XL888 in an in vivo model of NRAS-mutant melanoma. Mol Cancer Ther. 2013;12(6):901-912. doi:10.1158/1535-7163.MCT-12-1003
OncoTargets and Therapy

\section{Publish your work in this journal}

OncoTargets and Therapy is an international, peer-reviewed, open access journal focusing on the pathological basis of all cancers, potential targets for therapy and treatment protocols employed to improve the management of cancer patients. The journal also focuses on the impact of management programs and new therapeutic agents and protocols on patient perspectives such as quality of life, adherence and satisfaction. The manuscript management system is completely online and includes a very quick and fair peer-review system, which is all easy to use. Visit http://www.dovepress.com/ testimonials.php to read real quotes from published authors. 